\title{
Analysis of Product Quality and Service Quality on Customer Satisfaction at the Surya Mart Mart Business Center using the Structural Equation Modeling Method
}

\section{Analisa Kualitas Produk dan Kualitas Layanan Terhadap Kepuasan Pelanggan di Business Center Surya Mart Mart menggunakan Metode Structural Equation Modeling}

\author{
Yannu Prasetyo $^{1}$, Atikha Sidhi Cahyana ${ }^{2}$ \\ \{yannupras@gmail.com¹, atikhasidhi@umsida.ac.id ${ }^{2}$ \}
}

Prodi Teknik Industri Fakultas Sains dan Teknologi Universitas Muhammadiyah Sidoarjo ${ }^{1,2}$

\begin{abstract}
Service quality is a superior value for customers to improve business performance or company marketing represents a level of excellence to meet consumer expectations. Therefore, it is not necessary to know what factors affect product quality and service quality at the Surya Mart Business Center Surya Mart Business Center. Surya Mart Business Center Surya Mart's Business Center is located on campus 2 of the Muhammadiyah University of Sidoarjo (UMSIDA), the market is for students, lecturers, UMSIDA employees and the surrounding community. To find out the factors that affect product quality and service quality, research uses Structural Equation Modeling, which is ia statistical technique that is able to analyze the pattern of relationships between data constructs and indicators, one data construct and another, and direct measurement errors. The results showed that the highest loading factor value was 1.329 in the discount indicator, for the term indicator, namely the additional factor with a value of 0.664 . Test structural modeling on the relationship between constructs that have a casual or causal relationship. The results of this study, Variable Product Quality and Service Quality, the second variable has a significant influence on the Customer Satisfaction variable.
\end{abstract}

Keywords - Product Quality; Service Quality; Surya Mart Business Center

\begin{abstract}
Abstrak. Kualitas layanan merupakan penciptaan superior value bagi pelanggan untuk meningkatkan kinerja bisnis atau pemasaran perusahaan Merupakan tingkat keunggulan untuk memenuhi harapan konsumen. Oleh karena itu perlu diketahui faktor i-faktor apa saja yang mempengaruhi kualitas produk dan kualitas layanan pada business Center Surya Mart Business Center Surya Mart. Business Center Surya Mart Business Center Surya Mart terletak di kampus 2 Universitas Muhammadiyah Sidoarjo (UMSIDA), pasarnya adalah mahasiswa, dosen, pegawai UMSIDA dan masyarakat sekitar. Untuk mengetahui faktor-faktor yang mempengaruhi kualitas produk dan kualitas layanan penelitian ini menggunakan Structural Equation Modeling, yaitu suatu teknik statistik yang mampu menganalisis pola hubungan antara konstruk laten dan indikatornya, konstruk laten yang satu dengan lainnya, serta kesalahan pengukuran secara langsung. Hasil penelitian menunjukkan, inilah loading faktor yang paling tinggi 1,329 terdapat pada indikator Diskon, untuk indikator terkecil yaitu faktor tambahan dengan inilah 0,664. Uji struktual imodeling iini imengetahui ihubungan iantara ikonstruk iyang imempunyai ihubungan iCasual iatau isebab akibat. Hasil dari penelitian ini, Variabel Kualitas Produk dan Kualitas Layanan, kedua variabel ini memiliki pengaruh signifikan terhadap variabel Kepuasan Pelanggan.
\end{abstract}

Kata Kunci - Kualitas Produk; Kualitas Layanan; Business Center Surya Mart

\section{Pendahuluan}

Business Center Surya Mart ini terletak di kampus 2 UMSIDA yang dominan untuk pasarnya adalah mahasiswa, dosen, pegawai UMSIDA dan masyarakat sekitarnya. Untuk mengetahui seberapa puas konsumen terhadap kualitas layanan dan kualitas produk yang diberikan oleh Business Center Surya Mart terhadap pelanggan seperti fasilitas yang diberikan, pendingin ruangan, tersedianya stock yang diinginkan pelanggan, dan lain-lain, sehingga perlunya dilakukan pengukuran kepuasan pelanggan terhadap kualitas produk dan kualitas layanan untuk minimarket Business Center Surya Mart.

Berdasarkan masalah di atas maka penelitian ini ingin mengetahui faktor yang mempengaruhi kepuasan pembelian di Business Center Surya Mart dengan judul "Analisa Kualitas Produk Dan Kualitas Layanan Terhadap Kepuasan Pelanggan Di Business Center Surya Mart Menggunakan Metode Structural Equation Modeling”. 


\section{A. Business Center Surya Mart}

Business Center Surya Mart berupaya untuk memberikan pelayanan terbaik bagi para pelanggannya. Dalam menjalankan kegiatan usaha ini Business Center Surya Mart berdasarkan ajaran Islam. Hal - hal yang diajarkan dalam $\mathrm{Al}$ - Quran iakan dijalankan dalam usaha ini, seperti tidak menjual minuman, makanan dan barang i- barang yang termasuk haram, setiap produk yang di jual harus terdapat label halal dari MUI.

\section{B. Kualitas Produk}

Produk yang kualitas baik akan lebih menarik bagi konsumen, yang semakin berpengetahuan, lebih mencari kualitas terbaik dalam membeli produk yang dibutuhkan, sehingga penting bagi perusahaan untuk meningkatkan kualitas yang lebih berorientasi pada keputusan pembelian [8]. Kualitas produk sangat berpengaruh dalam meyakinkan para konsumen untuk melakukan keputusan pembelian, jika suatu produk bagus dan dapat memberikan kepuasan, maka dapat menaikkan kepercayaan pembelian terhadap produk tersebut, kualitas produk dapat di jadikan acuan untuk mengambil keputusan pembelian terhadap produk yang ditawarkan [9]. Tanggung jawab organisasi membatu memanajemen umum dan manajemen produksi dalam peningkatan kualitas produksi perusahaan. Khususnya fungsi strategi peningkatan kualitas produk merupakan suatu cara, teknik keterampilan dan sumber daya yang diperlukan untuk membantu produk dengan kualitas yang dapat diterima oleh pasar. Peningkatan kualitas produk dengan statistika dilaksanakan dengan menggunakan 3 elemen daras, yang semuanya berfokus pada proses organisasi adalah : (1). Perbaikan Proses, strategi ini bertujuan untuk menemukan solusi dengan menghilangkan akar penyebab masalah kinerja usaha dalam mencapai target. (2). Desain Ulang Proses, strategi ini bertujuan untuk membangun bisnis yang lebih baik, dengan cara menetapkan suatu proses pada proses yang baru. (3). Manajemen Proses, pada strategi manajemen proses, kebijakan organisasi dan pelaksanaan statistika menjadi yang menyatu dalam menjalakan program peningkatan kualitas produk [7].

\section{Kualitas Layanan}

Kualitas layanan, segala bentuk penyelenggaraan pelayanan yang diberikan secara maksimal oleh perusahaan dalam rangka memenuhi kebutuhan pelanggan yang sesuai dengan harapan pelanggan. Ada 5 Dimensi kualitas layanan dimensi tersebut adalah : (1). Bukti Fisik (Tangible), Meliputi penampilan fasilitas fisik, peralatan, kelengkapan komunikasi dan penampilan karyawan. (2). Kehandalan (Reliability), Kemampuan untuk memberikan pelayanan sesuai dengan janji yang ditawarkan. (3). Daya1Tanggap (Responsiveness), Respon atau kesigapan karyawan dalam membantu pelanggan dan memberikan pelayanan yang cepat dan tanggap. (4). Jaminan (Assurance), Kemampuan karyawan atas pengetahuan terhadap produk secara tepat, kualitas keramahtamahan, perhatian dan kesopanan karyawan, dan kemampuan dalam menanamkan kepercayaan pelanggan terhadap perusahaan. (5). Empati (Empathy), Perhatian secara individual yang diberikan perusahaan kepada pelanggan [6]. Konsumen pada menginginkan kualitas layanan yang baik. Kualitas layanan Kualitas produk dan, kepuasan pelanggan, dan profitabilitas sebuah perusahaan memiliki hubungan yang erat. Konsumen menginginkan kualitas pelayanan yang baik untuk dapat memuaskan pelanggan [4].

\section{Stucrual Equation Modelling}

SEM (Structural Equation Modelling) adalah salah satu dari analisis multivariat yang digunakan untuk menguji teori mengenai sekumpulan relasi dengan sejumlah variabel secara simultan. Structural Equation Modeling i(SEM) suatu teknik statistik yang mampu menganalisis pola hubungan antara konstruk laten dan indikatornya, konstruk laten yang satu dengan lainnya, serta kesalahan pengukuran secara langsung. Teknik analisis data dengan menggunakan Structural Equation Modeling (SEM) [5].

Structural Equation Modelling (SEM) juga dibedakan oleh dua karakteristik yaitu: Estimasi atau perkiraan hubungan dependensi berganda dan saling terkait. Kemampuan untuk mempresentasikan konsep yang tidak terlihat dalam hubungan-hubungan ini dan memperhitungkan pengukuran kesalahan di dalam proses estimasi. SEM juga mempunyai kemampuan untuk menggabungkan variabel yang tidak terlihat atau latent variables ke dalam analisis $[10]$.

Terdapat beberapa asumsi yang harus di pilihi pada analisa Structural Equation Modling i(SEM) yang dijelaskan sebagai berikut: (1). Ukuran Sampel, Ukuran sampel yang digunakan dalam analisa SEM berdasarkan karakteristik model struktural dan model pengukuran adalah 100 jika model menggunakan variabel leten sebanyak 5 atau lebih, variabel teramati sebanyak lebih dari i3 indikator. (2). Distribusi Normal Multivariat, Distribusi normal multivariat merupakan pengembangan dari distribusi normal iunivariat dengan jumlah variable lebih dari satu I[1].

Struktur Equation Modelling (SEM) adalah teknik yang memungkinkan hubungan yang terpisah untuk masing - masing variabel dependen. Hal ini ditandai dengan dua komponen dasar : (1) Model Struktural, Struktural adalah model path, yang berkaitan dengan hubungan antara variabel independen dan variabel dependen. (2) Model Pengukuran, Pengukuran memungkinkan peneliti untuk menggunakan beberapa variabel untuk satu independen atau variabel dependen [3]. 
Procedia of Engineering and Life Science Vol. 1. No. 2 Juni 2021

Seminar Nasional \& Call Paper Fakultas Sains dan Teknologi (SENASAINS $2^{\text {nd }}$ )

Universitas Muhammadiyah Sidoarjo

Prosedur SEM (Structural Equation Modeling) secara umum ada 7 tahapan, adalah: (1). Pengembangan Model Teoritis. (2). Pengembangan Diagram Jalur (3). Konversi Diagram Jalur ke dalam Persamaan. (4). Memilih Teknik Estimasi. (5). Menganalisa Kemungkinan Munculnya Masalah Identifikasi. i(6). Evaluasi Kriteria Goodnes Of Fit. (7). Interpretasi dan Modifikasi Model. [2].

\section{METODE PENELITIAN}

Berikut ini merupakan gambar dari flowchart penelitian.

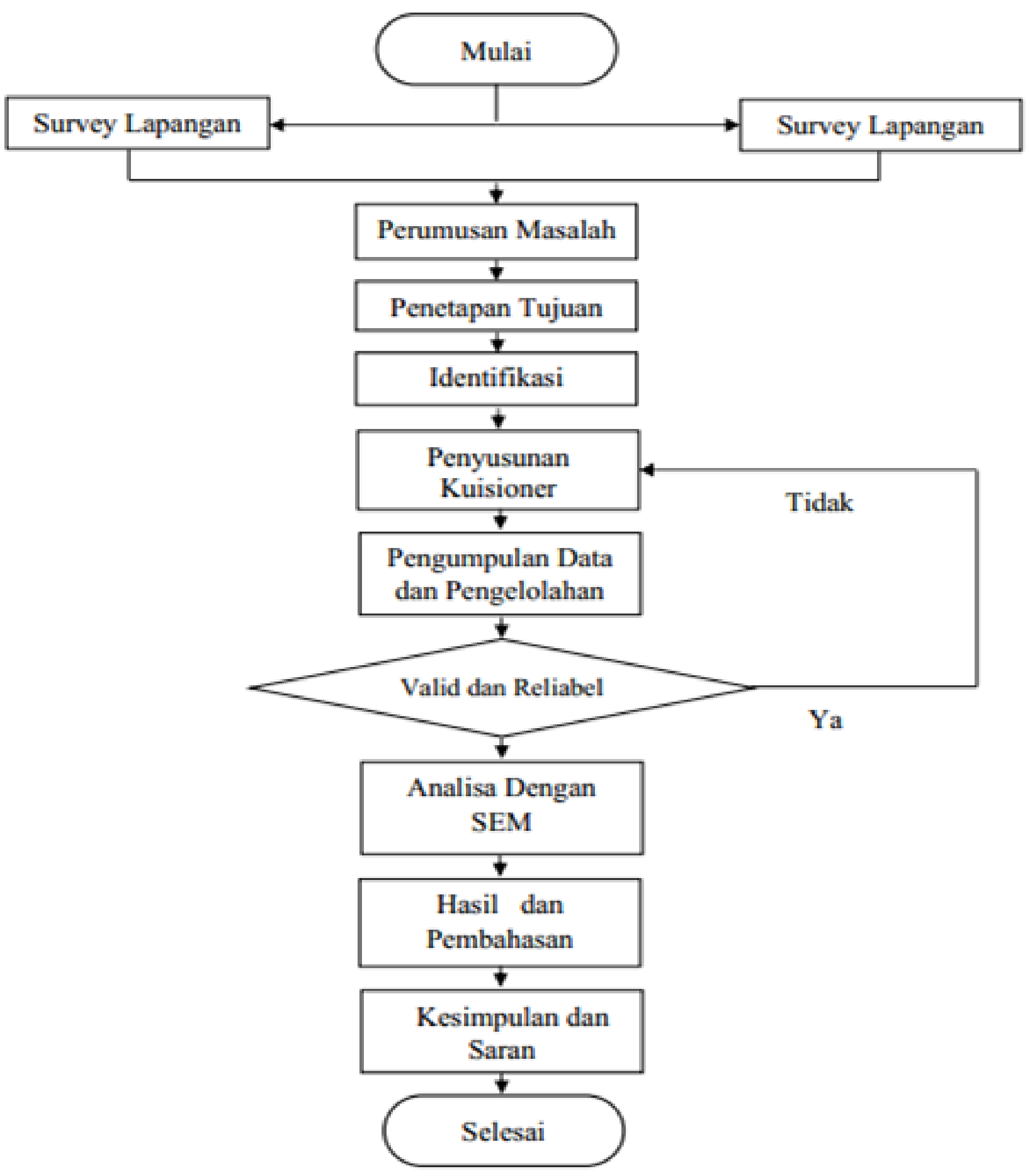

Gambar 1. Flowchart proses penelitian

A. Identifikasi Variabel 
Pada penelitian ini menggunakan dua variabel Ekosgen atau variabel Independet dan variabel endogen atau dependen: (1). Variabel Eksogen atau Variabel Independen, yaitu : (a). Kualitas Produk (X1). (b). Kualitas Layanan (X2). (2). Variabel Endogen atau Variabel Dependen, yaitu : (a). Kepuasan Pelanggan (Y1).

\section{B. Model Konseptual Penelitian}

Pada bagian ini menggambarkan dari konsep penelitian yang dilakukan hubungan dari setiap variabel

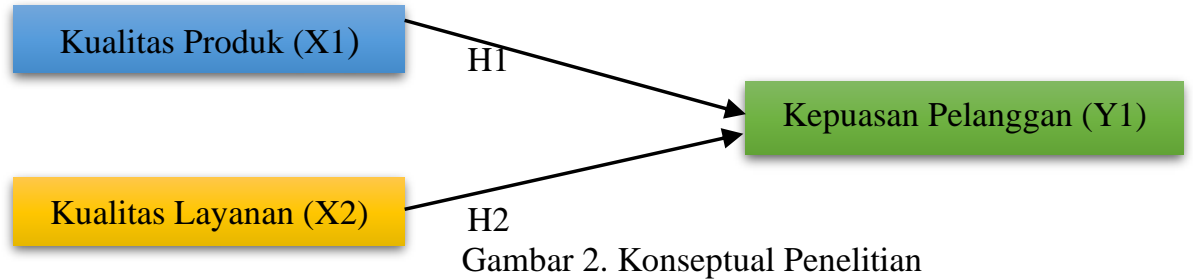

Hubungan variabel yang di tunjukan pada gambar di atas menggunakan hipotesa penelitian sebagai berikut :

H1 : Kualitas Produk dan kualitas Layanan secara bersamaan diduga berpengaruh terhadap kepuasan konsumen.

H2 : Kualitas Produk diduga berpengaruh terhadap kepuasan konsumen.

H3 : Kualitas Layanan diduga berpengaruh terhadap kepuasan konsumen.

Pada tahap ini terdapat dua jenis data yang digunakan dalam penelitian ini yaitu : (1). Data Primer, data primer yang dilakukan dalam penelitian ini di peroleh melalui penyebaran kuisoner pada responden yang telah sesuai dengan kriteria yang ditetapkan yaitu tentang kepuasan konsumen di Business Center Surya Mart. (2). Data Sekunder, data sekunder yang dikumpulkan bersumber dari masyarakat umum di sekitar Business Center Surya Mart dan konsumen yang datang.

Populasi penelitian ini adalah konsumen di Business Center Surya Mart. Responden merupakan konsumen yang datang i ke Business Center Surya Mart selama satu bulan.

Ukuran sampel = Indikator $\mathrm{x} 5$ sampai dengan 10

$$
=25 \text { indikator } \times 5=125
$$

\section{Hasil dan Pembahasan}

\section{A. Uji Reabilitas dan Validitas}

Hasil uji reliabilitas dinyatakan reliabel terbukti dari nilai Cronbach's Alpha yang dihasilkan variabel Kualitas Produk, Kualitas Layanan dan Kepuasan Pelanggan sebesar 0,942 lebih besar dari 0,60, maka variabel tersebut dinyatakan reliabel.

Nilai Cronbach's Alpha variabel Kualitas Produk memiliki nilai sebesar 0,861 yang lebih besar dari 0,60, maka variabel tersebut dinyatakan reliabel, nilai Cronbach's Alpha variabel Kualitas Layanan memiliki nilai sebesar 0,849, maka variabel tersebut dinyatakan reliabel, nilai Cronbach's Alpha variabel Kepuasan Pelanggan sebesar 0,870, maka variabel tersebut dinyatakan reliabel.

Data yang di uji pada penelitian ini yaitu data pendahuluan sebanyak 125 responden dengan menggunakan SPSS 16.0. Uji reabilitas digunakan untuk mengetahui tingkat konsistensi dari suatu instrumen jika nilai Cronbach's Alpha yang didapat di atas 0,600, maka instrumen yang di uji dapat dikatakan reliabel, nilai Corrected Item Total Correlation di atas 0,300, maka data tersebut dikatakan valid.

Data tabel 4.1, Nilai Corrected Item Total Correlation seluruh indikator pada pengujian data pendahuluan yaitu sebanyak 125 responden memilki nilai di atas 300, maka keseluruhan indikator dinyatakan valid.

Tabel I

\begin{tabular}{c|c|c|c|c}
\multirow{2}{*}{$\begin{array}{c}\text { Variabel Independen X1 } \\
\text { (Kualitas Produk) }\end{array}$} & Indikator & $\begin{array}{c}\text { Hasil validitas data pendahuluan (Kualitas Produk) } \\
\text { Correlation }\end{array}$ & Kode & Keterangan \\
\hline Daya Tahan & Kebutuhan & 0,720 & X1.1 & Valid \\
\cline { 2 - 5 } & Layak & 0,536 & X1.2 & Valid \\
\hline \multirow{2}{*}{ Reliabilitas } & Menarik & 0,621 & X1.3 & Valid \\
\cline { 2 - 5 } & Manfaat & 0,570 & X1.4 & Valid \\
\hline \multirow{2}{*}{ Estetika } & Keamanan & 0,468 & X1.5 & Valid \\
\cline { 2 - 5 } & Kenyamanan & 0,669 & X1.6 & Valid \\
\hline Kesan Kualitas & Business Center Surya Mart. & 0,664 & X1.7 & Valid
\end{tabular}



Produk
0,731
$\mathrm{X} 1.8$
Valid

Berdasarkan perhitungan nilai Corrected Item Total Correlation sebagaimana yang ditunjukkan dalam tabel 4.1, maka terlihat bahwa Corrected Item Total Correlation terlihat valid semua dan nilai terbesar terletak pada X1.8 (Produk) sebesar 0,731.

Tabel II

Hasil validitas data pendahuluan (Kualitas Layanan)

\begin{tabular}{c|c|c|c|c}
$\begin{array}{c}\text { Variabel Independen X2 } \\
\text { (Kualitas Layanan) }\end{array}$ & Indikator & $\begin{array}{c}\text { Corrected Item Total } \\
\text { Correlation }\end{array}$ & Kode & Keterangan \\
\hline \multirow{2}{*}{ Bukti Fisik } & Perhatian & 0,582 & X2.1 & Valid \\
\cline { 2 - 5 } & Solusi & 0,718 & X2.2 & Valid \\
\hline \multirow{2}{*}{ Kehandalan } & Pengetahuan luas & 0,658 & X2.3 & Valid \\
\cline { 2 - 5 } & Respon & 0,497 & X2.4 & Valid \\
\hline \multirow{2}{*}{ Daya tahan } & Perilaku & 0,534 & X2.5 & Valid \\
\cline { 2 - 5 } & Keluhan & 0,568 & X2.6 & Valid \\
\hline \multirow{2}{*}{ Jaminan } & Pelayanan & 0,646 & X2.8 & Valid \\
\cline { 2 - 5 } & Kenyamanan & 0,515 & X2.9 & Valid \\
\hline \multirow{2}{*}{ Empati } & Perhatian & 0,546 & X2.10 & Valid
\end{tabular}

Berdasarkan perhitungan nilai Corrected Item Total Correlation sebagaimana yang ditunjukkan dalam tabel 4.2, maka terlihat bahwa Corrected Item Total Correlation terlihat valid semua dan nilai terbesar terletak pada X2.2 (Solusi) sebesar 0,718.

Tabel III

Hasil validitas data pendahuluan (Kepuasan Pelanggan)

\begin{tabular}{c|c|c|c|c}
\multirow{2}{*}{$\begin{array}{c}\text { Variabel Dependen Y } \\
\text { (Kepuasan Pelanggan) }\end{array}$} & Indikator & $\begin{array}{c}\text { Corrected Item Total } \\
\text { Correlation }\end{array}$ & Kode & Keterangan \\
\hline Kualitas Produk & Rekomendasi & 0,715 & Y1.1 & Valid \\
\cline { 2 - 5 } & Kepuasan & 0,669 & Y1.2 & Valid \\
\hline Kualitas Pelayanan & Penampilan & 0,534 & Y1.3 & Valid \\
\cline { 2 - 5 } & Kenyamanan & 0,551 & Y1.4 & Valid \\
\hline Harga & Terjangkau & 0,640 & Y1.5 & Valid \\
\cline { 2 - 5 } & Diskon & 0,713 & Y1.6 & Valid \\
\hline Biaya & Tambahan & 0,670 & Y1.7 & Valid
\end{tabular}

Berdasarkan perhitungan nilai Corrected Item Total Correlation sebagaimana yang ditunjukkan dalam tabel 4.3, maka terlihat bahwa Corrected Item Total Correlation terlihat valid semua dan nilai terbesar terletak pada Y1.1 (Rekomendasi) sebesar 0,715.

Tabel IV

Hasil Reabilitas Data Pendahul

\begin{tabular}{c|c|c|c} 
Variabel & Jumlah Indikator & Cronbach's Alpha & Reabilitas \\
\hline Kualitas Produk & 8 & 0,861 & Reliabel \\
\hline Kualitas Layanan & 10 & 0,849 & Reliabel \\
\hline Kepuasan Pelanggan & 7 & 0,870 & Reliabel
\end{tabular}

Pada tabel 4.4 terlihat pula bahwa nilai Cronbach's Alpha dari keseluruhan variabel memiliki nilai di atas 600 maka keseluruhan variabel dikatakan reliabel.

\section{B. Rakapitulasi Tanggapan Responden}

Deskripsi dari tanggapan responden ini akan dijelaskan berdasarkan nilai frekuensi, skor, total dan rata - rata skor. Rumus yang digunakan untuk deskripsi tanggapan responden adalah :

Keterangan :

$$
R S=\frac{(m-n)}{b}=\frac{(4-1)}{4}=0.75
$$


Dari rumus tersebut ditetapkan bahwa 0,75 digunakan sebagai interval setiap katagori yang perinciannya sebagai berikut : (1). 1 sampai 1,75 adalah skor rendah. (2). 1,76 sampai 2,5 adalah skor sedang. (3). 2,51 sampai 3,25 adalah skor baik. (4). 3,26 sampai 4 adalah skor sangat baik.

\section{Pengujian Struktual Model}

Uji struktual modeling ini mengetahui hubungan antara konstruk yang mempunyai hubungan Casual atau sebab akibat. Dengan mengetahui uji struktual model dapat diketahui apakah model sudah fit pada setiap variabel eksogen dan endigen, jika ada yang tidak fit maka akan dimodifikasi sampai model menjadi fit.

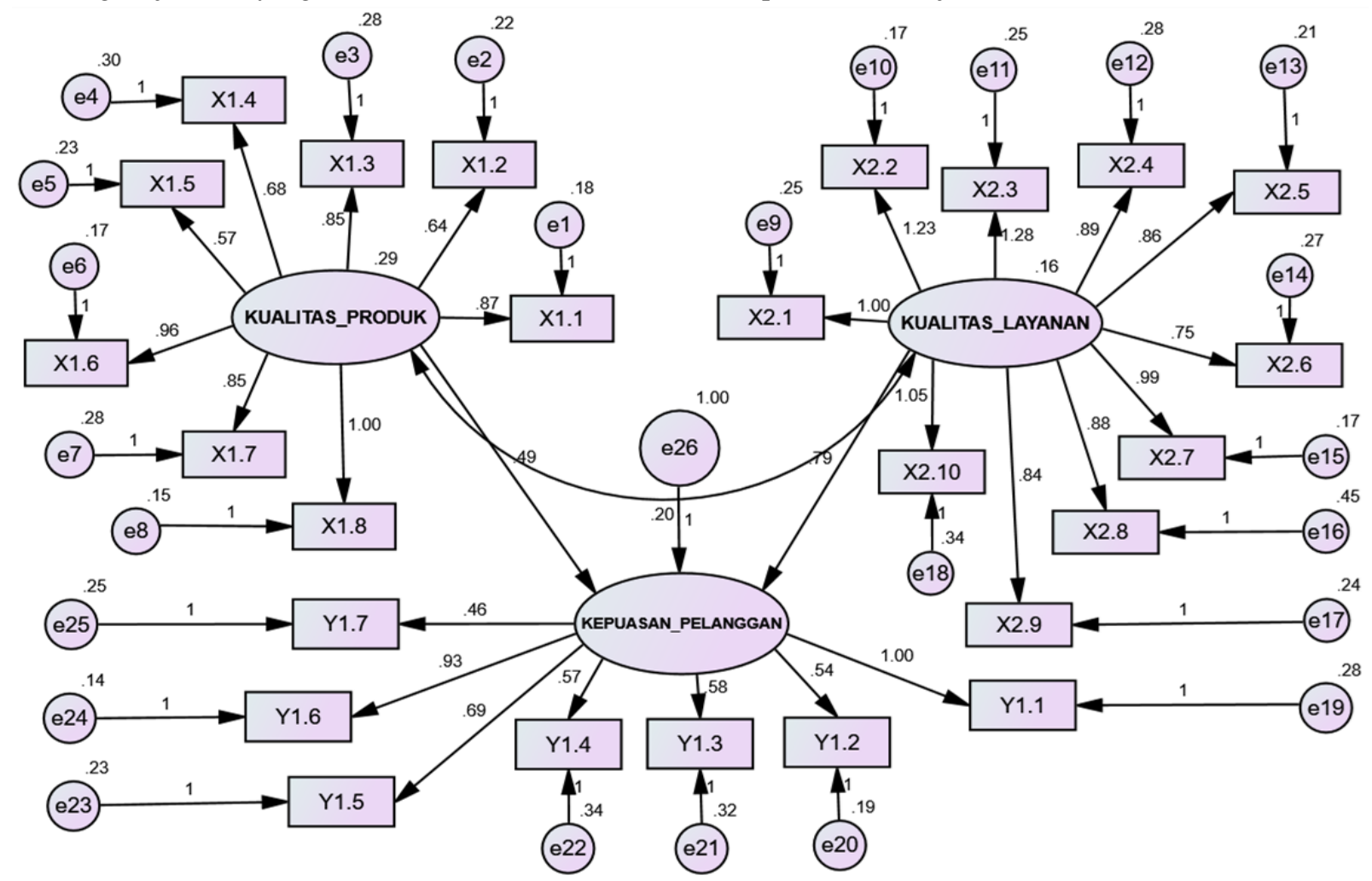

Gambar 6. Model SEM Keselruhan

Tabel X

Hasil Pengujian Struktual Model

\begin{tabular}{c|c} 
Goodness Of Fit Measure & Hasil \\
\hline Godness Of Index (GFI) & 0,677 \\
\hline Comparative Fit Index (CFI) & 0,655 \\
\hline Normo Fit Index (NFI) & 0,575
\end{tabular}

Dari hasil yang ditunjukan pada tabel 4.24 memberikan keterangan nilai Godness Of Index (GFI) 0,677, Comparative Fit Index (CFI) sebesar 0,655, Normo Fit Index (NFI) sebesar 0,575. Tapi pada model ini tidak ada satupun nilai yang di tas 0,9 atau mendekati 1 , maka model tidak fit dan harus di modifikasi. 
Procedia of Engineering and Life Science Vol. 1. No. 2 Juni 2021

Seminar Nasional \& Call Paper Fakultas Sains dan Teknologi (SENASAINS 2nd)

Universitas Muhammadiyah Sidoarjo

\section{Modifikasi Model}

roses modifikasi model pada dasarnya sama dengan mengulang proses pengujian data tersebut. Hanya di sini ada proses tambahan untuk mengidentifikasi variabel mana yang akan di olah lebih lanjut. Untuk memodifikasi model menggunakan rekomendasi yang di hasilkan oleh Software AMOS 21 terdapat pada manu Output yang bernama Modification Inside

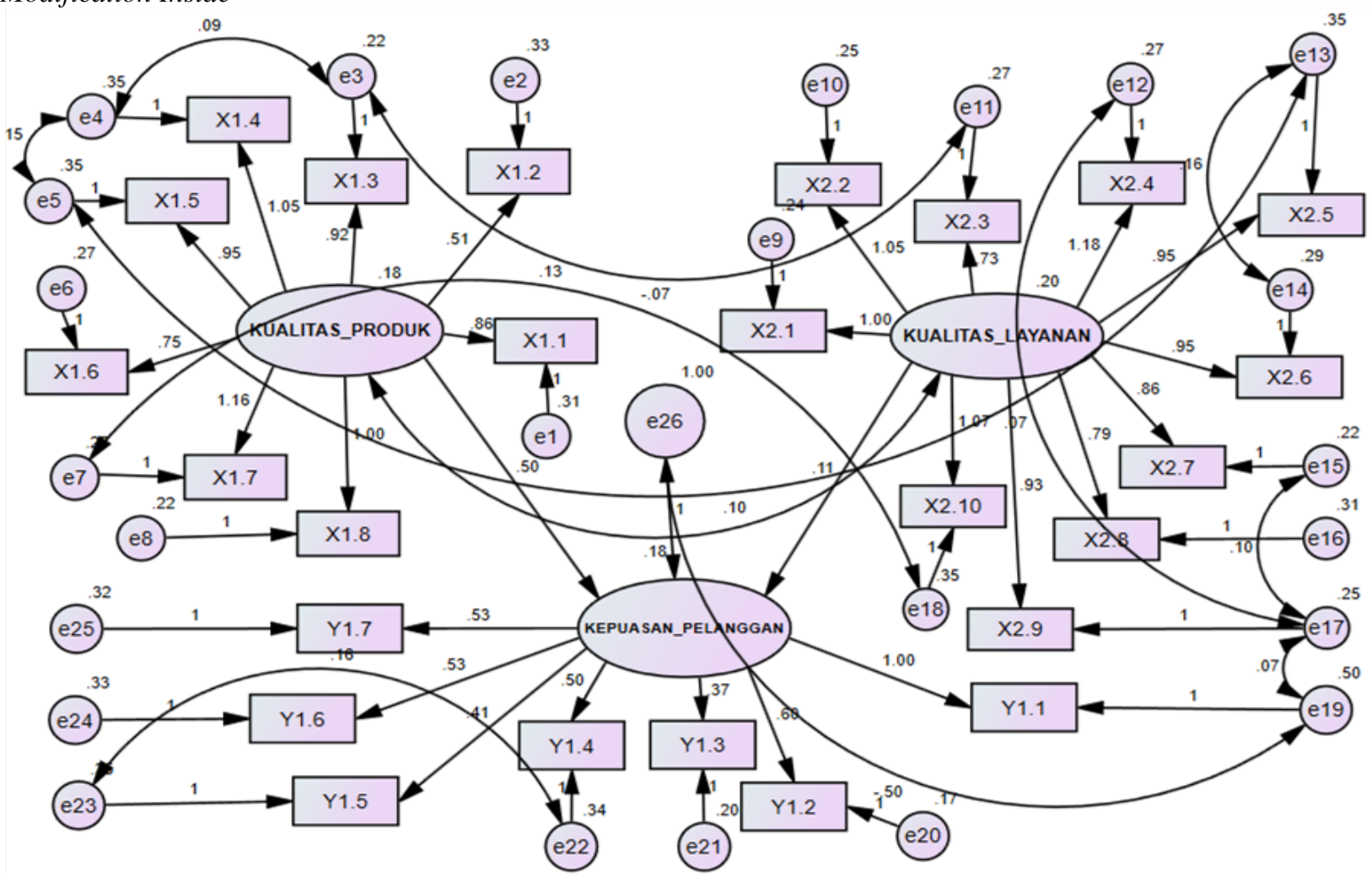

Gambar 7. Model SEM Modifikasi

Hasil dari uji struktual model yang telah dimodifikasi memberikan keterangan model Godness Of Index (GFI) dengan nilai 0,807, Normo Fit Index (NFI) dengan nilai 0,765 dan Comparative Fit Indeks (CFI) dengan nilai 0,904, yang dinyatakan fit karena ada parameter yang memenuhi nilai standar dengan nilai 0,9 atau mendekati 1 diantaranya terdapat pada parameter Comparative Fit Indeks (CFI) dengan nilai 0,904.

Hasil dari uji struktual model yang telah dimodifikasi memberikan keterangan model yang dinyatakan fit karena ada parameter yang memenuhi nilai standar dengan nilai 0,9 atau mendekati 1 diantaranya terdapat pada parameter Comparative Fit Indeks (CFI) dengan nilai 0,904.

\section{E. Analisis Model Strurctual Equation Modelling (SEM)}

Pada penelitian ini model yang dihasilkan menyatakan semua variabel memiliki pengaruh yang signifikan. Pada gambar ini menunjukkan model yang dihasilkan dalam proses penelitian ini

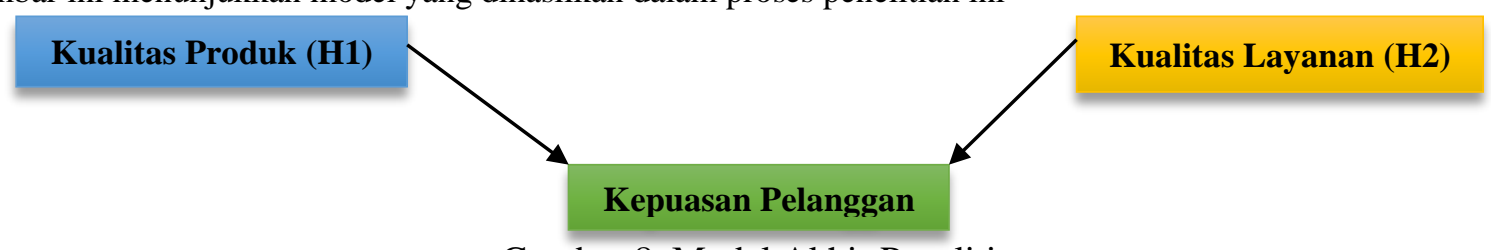

Gambar 8. Model Akhir Penelitian

Dari dua variabel yang mempengaruhi kepuasan pelanggan, kedua variabel memiliki pengaruh yang signifikan terhadap variabel kepuasan pelanggan dalam model dan hipotesa yng ditentukan.

\section{KESIMPULAN}

(1). Hasil dari uji analisis menggunakan metode Structural Equation Modelling sebagai berikut : (a). Kesimpulan nilai dari variabel kualitas produk untuk nilai dari X1.1( Kebutuhan) mencapai 1.000, X1.2 (Layak) mencapai 0,768, X1.3 (Menarik) mencapai 0,955, X1.4 (Manfaat) mencapai 0,764, X1.5 (keamanan) mencapai 0,682, X1.6 (kenyamanan) mencapai 1,176, X1.7 (Business Center Surya) mencapai 0,841, X1.8 (produk) mencapai 1,140. (b). 
Kesimpulan nilai dari variabel kualitas layanan menunjukkan bahwa nilai X2.1 (perhatian) mencapai 1,000, X2.2 (solusi) mencapai 1,329, X2.3 (Pengetahuan luas) mencapai 1,457, X2.4 (Respon) mencapai 1,070, X2.5 (Perilaku) mencapai 0,858, X2.6 (Keluhan) mencapai 0,771, X2.7 (pelayanan) mencapai 1,090, X2.8 (kenyamanan) mencapai 0,880, X2.9 (perhatian) mencapai 0,805, X2.10 (kemudahan) mencapai 1,286. (2). Pengaruh kualitas produk dan kualitas pelanggan terhadap Business Center Surya Mart yaitu dari variabel Kualitas Produk dan Kualitas Layanan dari kedua variabel memiliki pengaruh signifikan terhadap variabel Kepuasan Pelanggan.

Saran untuk penelitian selanjutnya agar menambahkan variabel - variabel yang lain sehingga analisis tingkat kepuasan konsumen dan Penelitian tersebut di harapkan dapat membantu Business Center Surya Mart agar lebih berkembang lagi.

\section{REFERENSI}

[1] Y. C. Anam and A. Suharsono, "Pemodelan Faktor-faktor yang Mempengaruhi Kinerja Karyawan PT Djarum Unit Karangbener, Kudus-Jawa Tengah Menggunakan Structural Equation Modeling,” J. Sains dan Seni ITS, vol. 7, no. 2, pp. 2-9, 2019, doi: 10.12962/j23373520.v7i2.35257.

[2] Syarah Widyaningtyas, Triastuti Wuryandari, and Moch. Abdul Mukid, "PENGARUH MARKETING MIX TERHADAP KEPUASAN DAN LOYALITAS KONSUMEN MENGGUNAKAN METODE STRUCTURAL EQUATION MODELLING (SEM) (Studi Kasus Toserba Toko Tembalang ‘Totem'),” J. Gaussian, vol. 5, no. 3, pp. 553-562, 2016.

[3] F. Aminah, A. Suharsono, and I. Ahmad, "Pengaruh Rasio Keuangan terhadap Nilai Perusahaan pada Sektor Perbankan yang Tercatat di Bursa Efek Indonesia Menggunakan Metode Structural Equation ModellingPartial Least Square,” J. Sains dan Seni ITS, vol. 5, no. 2, pp. 402-407, 2016.

[4] M. R. Masitoh, H. A. Wibowo, and D. Sunaryo, "Pengaruh Kualitas Pelayanan, Kepuasan, dan Kepercayaan Merek terhadap Niat Pembelian Ulang di Toko Online Tokopedia,” Manajemen, vol. 8, no. 1, pp. 60-77, 2018.

[5] R. Sukwadi, M. W. Inderwati, and M. I. Yemima, "Perilaku konsumen dalam pemilihan online shop instagram,” J. Metris, vol. 17, pp. 123-132, 2016.

[6] J. Sepang, L. Mananeke, and S. Sahanggamu, "Analisis Kualitas Layanan, Servicescape Dan Kepercayaan Terhadap Kepuasan Nasabah Pada Pt. Bank Sinarmas Bitung,” J. Ris. Ekon. Manajemen, Bisnis dan Akunt., vol. 3, no. 1, pp. 1084-1095, 2015, doi: 10.35794/emba.v3i1.7868.

[7] R. Wenas, H. Tawas, and A. Rumengan, "Analisis Citra Merek, Kualitas Produk, Dan Strategi Harga Terhadap Keputusan Pembelian Mobil Daihatsu Ayla Cabang Manado," J. Ris. Ekon. Manajemen, Bisnis dan Akunt., vol. 3, no. 2, pp. 684-694, 2015, doi: 10.35794/emba.v3i2.8696.

[8] S. Moniharapon and J. Ginting, "Pengaruh Citra Merek Dan Kualitas Produk Terhadap Keputusan Pembelian Mobil Daihatsu Xenia Pada Pt. Astra Internasional Daihatsu Manado,” J. Ris. Ekon. Manajemen, Bisnis dan Akunt., vol. 3, no. 1, pp. 493-501, 2015, doi: 10.35794/emba.v3i1.7192.

[9] S. Kharisma, Z. Arifin, and W. Wilopo, "PENGARUH INTERNATIONAL BRAND IMAGE DAN KUALITAS PRODUK TERHADAP KEPUTUSAN PEMBELIAN (Survei pada pemilik smartphone Lenovo di Kawasan Asia Tenggara)," J. Adm. Bisnis S1 Univ. Brawijaya, vol. 50, no. 1, pp. 91-97, 2017.

[10] I. Manajemen and P. Dengan, “Analisa Hubungan Faktor-Faktor Yang Mempengaruhi,” no. November, pp. $1-9,2016$. 